\title{
Semilunar Granule Cells: Glutamatergic Neurons in the Rat Dentate Gyrus with Axon Collaterals in the Inner Molecular Layer
}

\author{
Philip A. Williams, Phillip Larimer, Yuan Gao, and Ben W. Strowbridge \\ Department of Neurosciences, Case Western Reserve University, Cleveland, Ohio 44106
}

\begin{abstract}
Synaptic reorganization of the dentate gyrus inner molecular layer (IML) is a pathophysiological process that may facilitate seizures in patients with temporal-lobe epilepsy. Two subtypes of IML neurons were originally described by Ramón y Cajal (1995), but have not been thoroughly studied. We used two-photon imaging, infrared-differential interference contrast microscopy and patch clamp recordings from rat hippocampal slices to define the intrinsic physiology and synaptic targets of spiny, granule-like neurons in the IML, termed semilunar granule cells (SGCs). These neurons resembled dentate granule cells but had axon collaterals in the molecular layer, significantly larger dendritic arborization in the molecular layer, and a more triangular cell body than granule cells. Unlike granule cells, SGCs fired throughout long-duration depolarizing steps and had ramp-like depolarizations during interspike periods. Paired recordings demonstrated that SGCs are glutamatergic and monosynaptically excite both hilar interneurons and mossy cells. Semilunar granule cells appear to represent a distinct excitatory neuron population in the dentate gyrus that may be an important target for mossy fiber sprouting in patients and rodent models of temporal lobe epilepsy.
\end{abstract}

Key words: hippocampus; two-photon imaging; EPSP; dentate gyrus; dentate hilus; mossy cell; epilepsy

\section{Introduction}

The inner molecular layer (IML) of the dentate gyrus is a poorly understood region that is critically involved in temporal lobe epilepsy. The dentate gyrus circuitry is reorganized in patients with this form of epilepsy because of sprouting of granule cell (GC) axons into the dentate IML (Houser et al., 1990). Although the initial trigger for the granule cell axon sprouting appears to be the loss of glutamatergic mossy cells that normally reside in the dentate hilus and project to the IML (Scharfman and Schwartzkroin, 1988; Jiao and Nadler, 2007), the functional consequences of dentate reorganization is controversial. Some studies using animal models of temporal lobe epilepsy suggest that sprouted granule cell axons selectively contact granule cell dendrites, increasing network excitability (Tauck and Nadler, 1985), whereas other studies find that sprouting GC axons function to enhance recurrent inhibition by increasing the excitatory drive to inhibitory interneurons (Sloviter, 1992).

Despite the central role the IML plays in seizure-related synaptic reorganization, relatively little is known about the cell types that normally populate this layer. Ramón y Cajal (1995) described both sparsely spiny interneurons and densely spiny,

Received Sept. 5, 2007; revised 0ct. 23, 2007; accepted Nov. 9, 2007.

This work was supported by National Institutes of Health (NIH) Grant R01-NS33590 to B.W.S. P.A.W. was supported by a postdoctoral fellowship from the Epilepsy Foundation. P.L. was supported by NIH Training Grant AG00271. We thank Drs. Jason Frazier and Todd Pressler for their constructive comments on this manuscript.

Correspondence should be addressed to Dr. Ben W. Strowbridge, Department of Neurosciences, Case Western Reserve University, 10900 Euclid Avenue, Cleveland, OH 44106. E-mail: bens@case.edu.

D0I:10.1523/JNEUROSCI.4053-07.2007

Copyright $\odot 2007$ Society for Neuroscience ～0270-6474/07/2713756-06\$15.00/0 granule-like cells in this layer. No previous studies have recorded from the granule-like cells Ramón y Cajal (1995) described in the IML. In nonepileptic rodents, dentate granule cell dendrites occupy the molecular layer whereas their axons project exclusively toward the hilus where they ramify before innervating more distant targets (Claiborne et al., 1986). Little is known about whether granule-like IML cells are similarly polarized and contact the same neuronal subpopulations as granule cells.

Using patch clamp recording and two-photon (2P) visualization, we find that although spiny IML neurons have some morphological similarities to granule cells, they often generate axon collaterals in the IML, and thus may contact different neuronal populations than granule cells. Spiny IML neurons also have different functional properties than granule cells and are more strongly activated by hilar stimulation than granule cells. The results suggest that spiny IML cells are morphologically and physiologically distinct from granule cells.

\section{Materials and Methods}

Horizontal slices containing the ventral hippocampus (300 $\mu \mathrm{m}$ thick) from 14- to 25-d-old Sprague Dawley rats were prepared as described previously (Frazier et al., 2003) and placed in a submerged recording chamber on the stage of an upright microscope (Axioskop FS; Zeiss, Thornwood, NY). Slices were continuously perfused at $30^{\circ} \mathrm{C}$ with standard artificial CSF that contained (in $\mathrm{mm}$ ) $124 \mathrm{NaCl}, 3 \mathrm{KCl}, 1.23$ $\mathrm{NaH}_{2} \mathrm{PO}_{4}, 1.2 \mathrm{MgSO}_{4}, 26 \mathrm{NaHCO}_{3}, 10$ dextrose, and $2.5 \mathrm{CaCl}_{2}$ that was equilibrated with $95 \% \mathrm{O}_{2} / 5 \% \mathrm{CO}_{2}$. Whole-cell current-clamp recordings were made using an internal solution that contained (in mM) $140 \mathrm{~K}$ methylsulfate, $4 \mathrm{NaCl}$, 10 HEPES, 0.2 EGTA, 4 MgATP, $0.3 \mathrm{Na}_{3} \mathrm{GTP}$, and 10 phosphocreatine. The same internal solution with the addition of 10 mM BAPTA was used for the Ca chelating experiment in Figure 2 B. All 


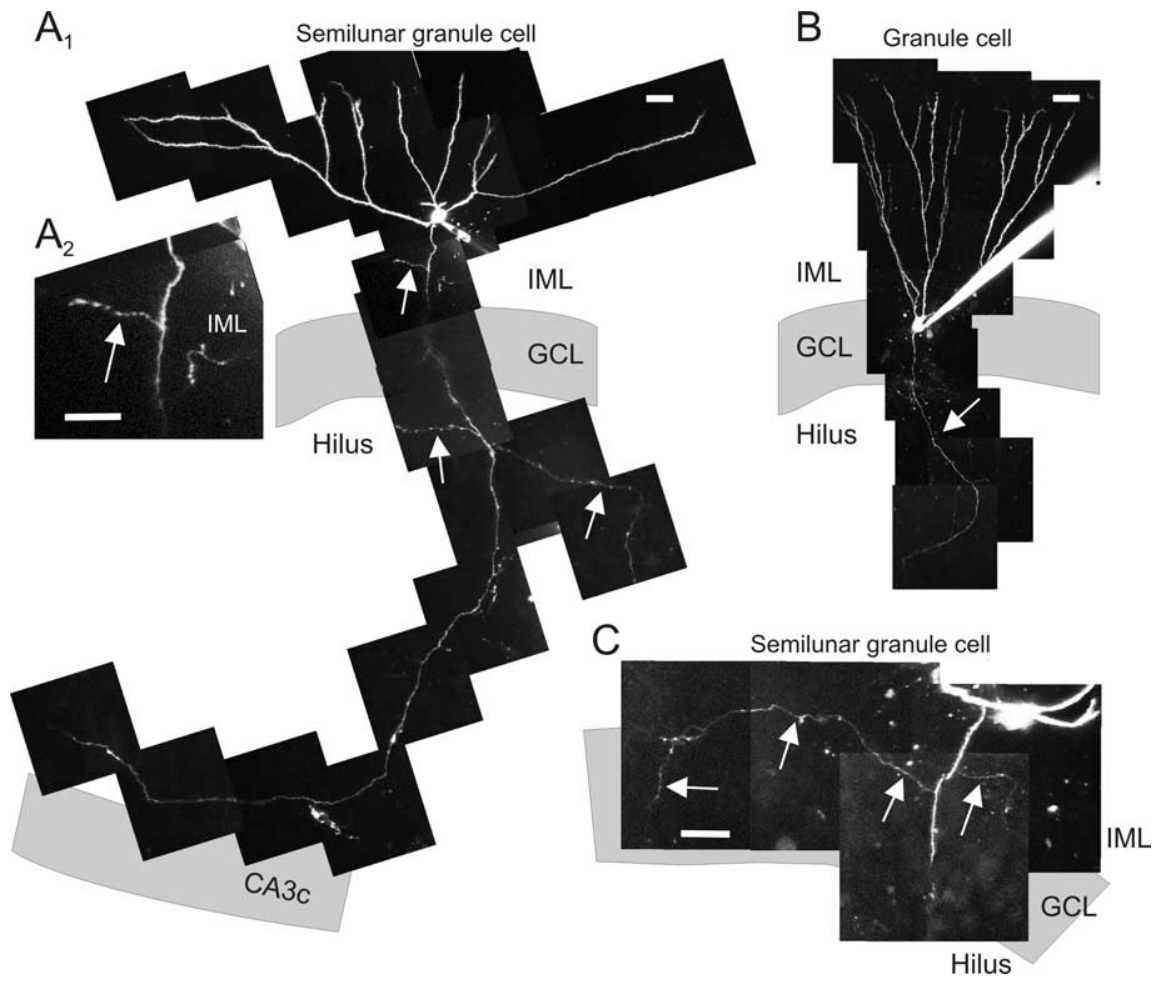

Figure 1. Two-photon reconstructions of $S G C S$ and $G C s . A_{1}$, Reconstruction of a $S G C$ filled with Alexa594. Axon collaterals are visible in both the hilus, directed toward CA3C, and in the IML. $\boldsymbol{A}_{2}$, Enlargement of IML axon collateral $\left(\boldsymbol{A}_{1}, \boldsymbol{A}_{2}\right.$, arrows). $\boldsymbol{B}$, Reconstruction of a GC with an axon in the hilus. $C$, Partial reconstruction of a SGC with axon collaterals (arrows) in the IML/GCL border. Scale bars: $25 \mu \mathrm{m}$.

postnatal day 14 (P14)-P25 rat slices using standard whole-cell patch clamp methods. We visualized a subset of these neurons ( $n=60)$ using two-photon microscopy after filling them with Alexa594. We often (72.5\% of IML recordings) found fastspiking neurons that discharged intermittently during 2-s-long depolarizing steps (data not shown). However, we also found a subpopulation of neurons $(27.5 \%$ of IML cells) whose morphology and intrinsic physiology did not resemble fastspiking interneurons.

As shown in Figure $1 \mathrm{~A}$, nonintermittently firing IML neurons have polarized dendrites that project toward the hippocampal fissure and an axon that penetrates the granule cell layer and ramifies in the hilus. In several reconstructions ( 3 of 10 ), including the example shown in Figure $1 A$, the axon reaches the hippocampal CA3c subfield. Although the dendritic polarization and axonal trajectory of this subpopulation of IML neurons resembles dentate GCs (Fig. 1B), this subpopulation of IML cells extends their dendrites over a significantly larger lateral distance than the control population of eight filled and reconstructed GCs located in the superficial half of the GCL, most near the border with the IML (maximal lateral extent in IML neurons, $420.3 \pm 26.8$ vs $284.9 \pm 33.7$ $\mu \mathrm{m}$ for superficial GCs, measured at the

drugs were obtained from Sigma (St. Louis, MO). Alexa594 was obtained from Invitrogen (Eugene, OR).

Neurons were visualized using infrared-differential interference contrast optics and a CCD camera (Cohu, Poway, CA). Neuronal morphology was defined after filling neurons with Alexa594 through the patch pipette and visualizing labeled processes using 2-photon microscopy, as described previously (Pressler and Strowbridge, 2006). Shape factor was defined by the ratio of the two longest orthogonal diameters contained within the cell body. Whole-cell recordings were made using an Axopatch 1D amplifier (Molecular Devices, Sunnyvale, CA). Voltage records were low-pass filtered at $2 \mathrm{kHz}$ and sampled at $5 \mathrm{kHz}$ using an ITC-18 16-bit analog-to-digital converter (Instrutech, Port Washington, NY) using custom software written in Visual Basic 6 (Microsoft, Redmond, WA). Custom Visual Basic routines and Origin 7.5 (OriginLab, Northhampton, MA) were used to analyze intrinsic and synaptic responses. Input resistance was assayed by measuring responses to small hyperpolarizing current steps applied near rest. The amplitude of the slow spikeevoked afterhyperpolarization (AHP) was calculated by averaging the membrane potential 25-30 ms after AP onset. Mean AP time was defined by the average latencies of all APs evoked by a $2 \mathrm{~s}$ depolarizing step. Synaptic responses were evoked using tungsten monopolar electrodes (FHC, Bowdoin, ME) connected to a constant-current stimulus isolation unit (model A360; World Precision Instruments, Sarosota, FL). Jitter was assessed by calculating the SD of the postsynaptic response latency. Pharmacological agents were applied by switching the perfusion solution. Voltages presented are not corrected for the liquid junction potential. Except where noted, statistical significance was determined using the Student's $t$ test. Data are presented as mean \pm SEM.

\section{Results}

We first asked whether noninterneuronal cell types exist in the molecular layer. We recorded from 233 neurons in the IML and 64 granule cells in the superficial granule cell layer (GCL) in hippocampal fissure; $217.2 \pm 16.7$ vs $141.0 \pm 15.5 \mu \mathrm{m}$, measured halfway between the cell body and fissure; both comparisons significantly different; $p<0.01$.) The larger lateral spread of IML cell dendrites is consistent with the gradient of dendritic arborization reported previously for GCs located at different positions within the GCL (for review, see Shapiro and Ribak, 2005). Granule cell-like neurons in the IML also have significantly different cell body shape than GCs located in the GCL (shape factor, $0.77 \pm 0.02$ for IML cells vs $0.59 \pm 0.05$ for GCs; $n=22$ and 15 , respectively; $p<0.001$.) The mean area of granule-like IML cell bodies $\left(203.0 \pm 10.9 \mu \mathrm{m}^{2}\right)$ is similar to superficial GCs $\left(190.8 \pm 11.9 \mu \mathrm{m}^{2} ; p>0.05\right)$.

Approximately half of the noninterneuronal IML cells we reconstructed ( 4 of 10 cells) had axon collaterals in the molecular layer (Figs. $1 A_{2}, C$ ). The mean extent of these axon collaterals is $54.4 \pm 21 \mu \mathrm{m}$ and they generate an average of $1.8 \pm 0.4$ branches. Axon collaterals in the IML initially are oriented parallel to the GCL and often (three of four reconstructed cells) generate secondary collaterals that enter the GCL (Fig. 1C). The IML/GCL axon collaterals contain numerous varicosities $(6.6 \pm 1.6 \mu \mathrm{m}$ spacing). The frequency of varicosities in IML/GCL axon collaterals is significantly greater than in hilar axon collaterals in the same population of filled IML cells $(13.2 \pm 1.8 \mu \mathrm{m}$ spacing; $p<$ 0.01). Although all eight superficial GCs we reconstructed had axon collaterals that ramified in the hilus, none had axon collaterals in either the GCL or IML. Because the subpopulation of IML cells we identified had overlapping morphological characteristics with GCs (polarized dendrites, similar size somata, primary axon directed toward the hilus), but had a different cell body shape, we chose to adopt Ramón y Cajal's (1995) terminology for granule- 
like cells in the IML, semilunar granule cells (SGCs), when referring to these neurons.

Both GCs and SGCs rest at relatively hyperpolarized membrane potentials $(-74.7 \pm 6.3$ and $-78.0 \pm 8.1 \mathrm{mV}$, respectively; $n=10$ and $11 ; p>0.05)$ and have overshooting action potentials (AP amplitude, $79.0 \pm 4.9$ and $85.6 \pm 2.3 \mathrm{mV}$, respectively; $p>0.05)$. However, SGCs differ dramatically from GCs in their responses to long-duration current steps. As shown in Figure $2 A_{1}$, SGCs discharge throughout $2 \mathrm{~s}$ depolarizing steps whereas GCs tend to fire predominately only during the initial 50-100 ms of the response. This difference in spike frequency adaptation is present in responses to graded current steps and is statistically significant (mean AP time in responses to $2 \mathrm{~s}$ steps, $614.9 \pm 31 \mathrm{~ms}$ for SGCs vs $83.8 \pm 17 \mathrm{~ms}$ for GCs; $n=15$ for both groups; $p<$ 0.001). SGCs also generate depolarizing ramp potentials before each AP (Fig. $2 \mathrm{~A}_{2}$, left, filled arrows) and have pronounced spike afterhyperpolarizations (open arrows) (mean AHP amplitude $-8.0 \pm 0.8$ $\mathrm{mV} ; n=15)$ that are significantly smaller in GCs $(-0.81 \pm 1.4 \mathrm{mV} ; n=15 ; p<$ 0.01 ) (Fig. $2 A_{2}$, right).

The difference in spike frequency adaptation between SGCs and GCs may reflect, in part, different intrinsic Ca dynamics as intracellular perfusion with internal solutions containing BAPTA ( $10 \mathrm{~mm}$ ) reduces adaptation and promotes tonic firing in control GCs (Fig. $2 B$ ). The mean AP time in BAPTA-filled GCs $(736.7 \pm 65 \mathrm{~ms} ; n=$ 5 cells) is significantly greater than control GCs (recorded with internal solutions containing $0.2 \mathrm{~mm}$ EGTA; $p<0.001$ ) and is not significantly different from SGCs (also with $0.2 \mathrm{~mm}$ EGTA; $p>0.05$ ) (Fig. 2C). However, the amplitude of the AHP after each spike is not significantly different between BAPTA-filled $(-1.4 \pm 1.0$ $\mathrm{mV} ; n=5)$ and control GCs $(p>0.05)$, suggesting that SGCs and GCs likely also posses different constellations of intrinsic conductances. Both input resistance $(128.3 \pm 17.5 \mathrm{M} \Omega$ for SGCs vs $320.5 \pm 77.3 \mathrm{M} \Omega$ for GCs; $n=11$ and 10, respectively; $p<0.05$ ) and membrane time constant $(19.6 \pm 3.4 \mathrm{~ms}$ for SGCs vs $28.3 \pm 10.6 \mathrm{~ms}$ for GCs; $p<0.05)$ also differ significantly between SGCs and control GCs.

\section{Semilunar granule cells are glutamatergic and synapse onto hilar neurons}

Next, we used two-photon guided paired recordings (Pressler and Strowbridge, 2006) to determine the neurotransmitter released by SGCs. We recorded from SGC/hilar cell pairs in which the hilar cell was located near a visualized SGC axon collateral. In four paired recordings ( $9 \%$ of all paired recordings), APs in the SGCs triggered EPSPs in hilar neurons. Two postsynaptic neu-
$A_{1}$ Semilunar Granule Cell
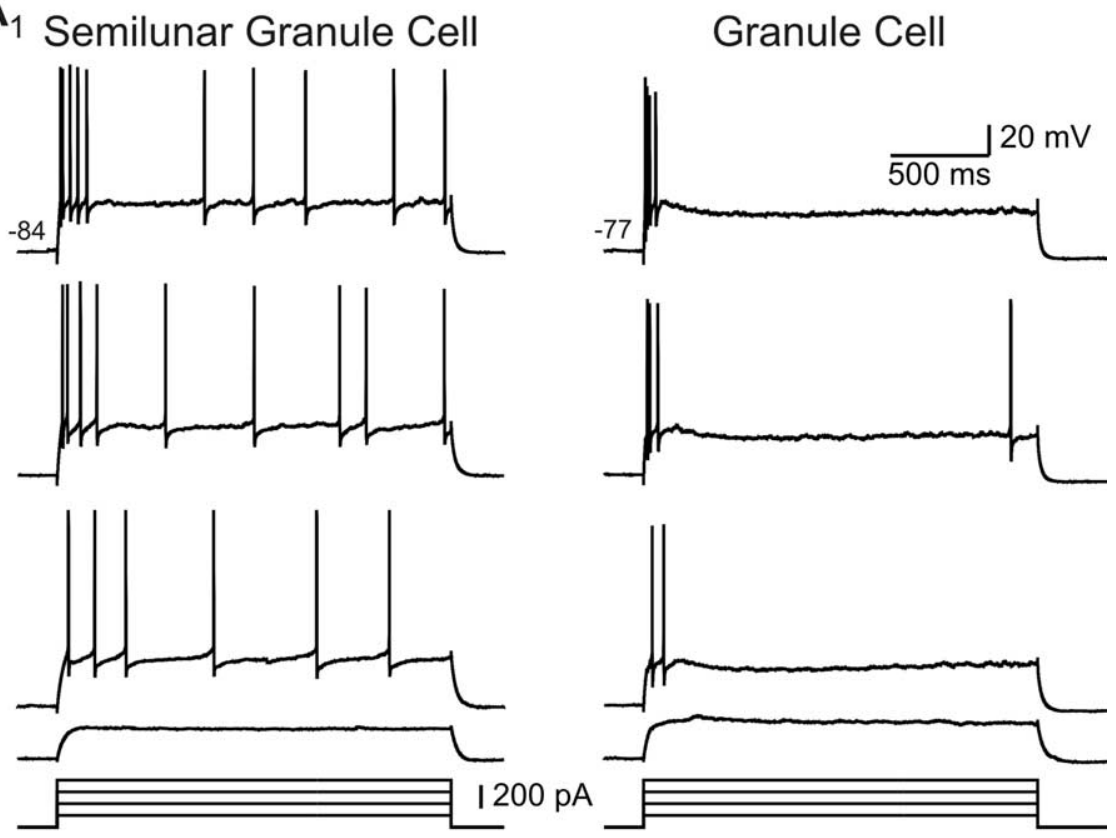

$A_{2}$
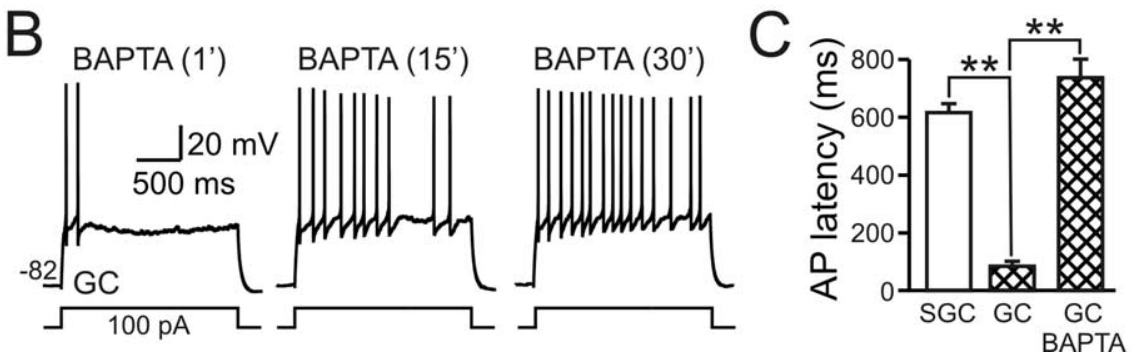

Figure 2. SGCs have less spike frequency adaptation than GCs. $\boldsymbol{A}_{1}$, Responses to graded $2 \mathrm{~s}$ depolarizing steps. SGCs discharge throughout each suprathreshold step whereas $\mathrm{GCs}$ generate the vast majority of their spikes within the first $100 \mathrm{~ms}$. $\boldsymbol{A}_{2}$, Enlargement of the initial responses in the SGC and GC shown in $\boldsymbol{A}_{1}$ to a 200 and 400 pA steps, respectively. Most spikes in SGCS are intrinsic response is recorded in GCs under control conditions. Action potentials truncated. $\boldsymbol{B}$, Chelation of intracellular $\mathbf{C a}$ with 10 mм BAPTA reduces spike frequency adaptation in GCs. C, Summary of the average latency of the spikes evoked by 2 s depolarizing steps in 15 SGCs, $15 \mathrm{GCs}$, and $5 \mathrm{GCS}$ recorded with an internal solution containing 10 mM BAPTA. ${ }^{* *} p<0.001$.

rons were hilar mossy cells, based on the presence of thorny excrescences on proximal dendrites, conventional spines on distal dendrites, and an irregular firing pattern in response to $2 \mathrm{~s}$ depolarizing steps (Scharfman and Schwartzkroin, 1988) (Fig. 3A). The other two postsynaptic targets appeared to be hilar interneurons based on their sparsely spiny dendrites and intermittent discharges in responses to depolarizing steps (Scharfman et al., 1990).

The recordings in Figure $3 B$ illustrate a SGC-to-hilar mossy cell paired recording. Action potentials in SGCs evoke largeamplitude (1.45 $\pm 0.14 \mathrm{mV} ; n=4$ pairs) (Fig. $3 C$ ), short-latency (1.52 $\pm 0.04 \mathrm{~ms} ; n=4$ pairs) (Fig. $3 D$ ) EPSPs in hilar cells held near rest. SGC-evoked EPSPs triggered APs in hilar neurons held 


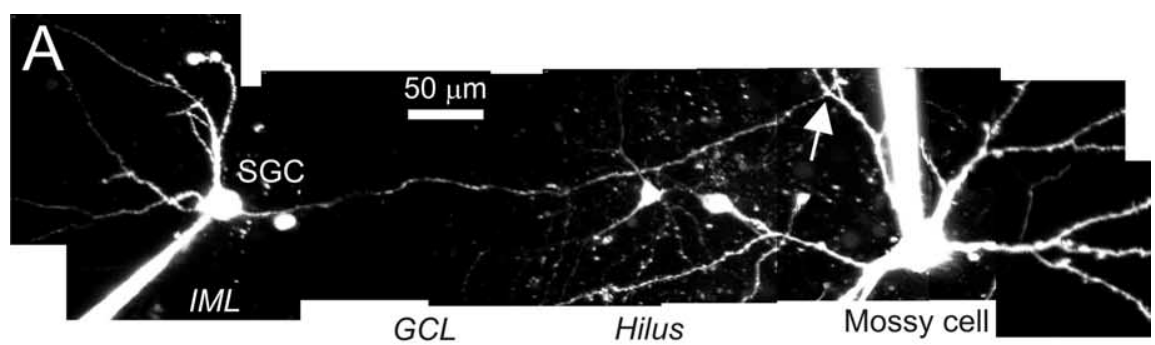

B
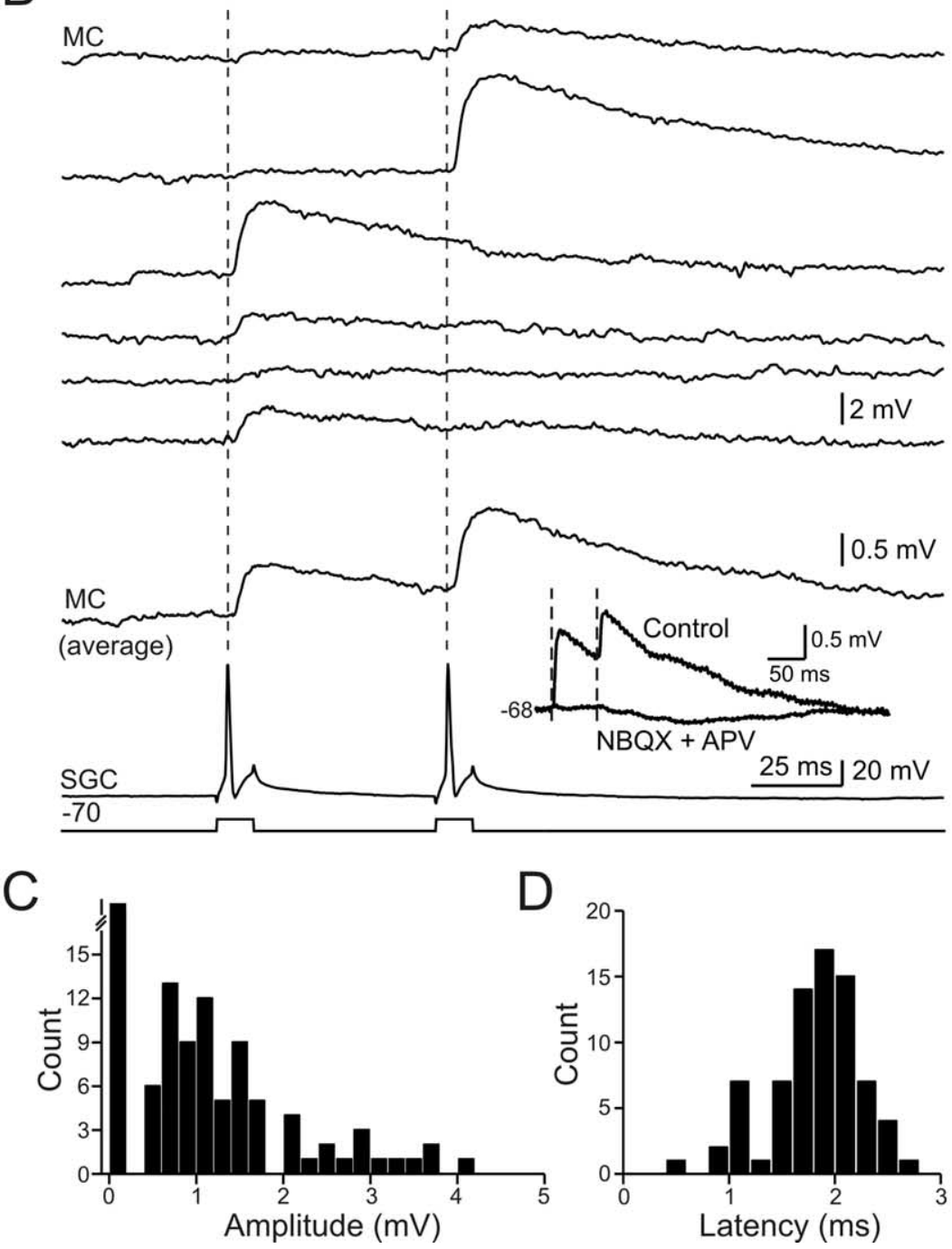

Figure 3. SGCS are excitatory and synapse onto hilar mossy cells. $\boldsymbol{A}$, Montage showing a SGC and a postsynaptic hilar mossy cell, both filled with Alexa594. The SGC axon appears to contact the mossy cell dendrite (arrow) after it bifurcates, $72 \mu \mathrm{m}$ from the center of the cell body. $\boldsymbol{B}$, Sequential responses to SGC action potentials. Approximately $45 \%$ of presynaptic APs triggered detectable short-latency EPSPs in the mossy cell (MC). Average postsynaptic response from 15 consecutive responses shown in bottom trace; $-64 \mathrm{mV}$ resting potential. The inset shows block of postsynaptic responses recorded in the mossy cell by $10 \mu \mathrm{M}$ NBQX and $50 \mu \mathrm{m}$ D-APV. Each trace is the average of $10-20$ consecutive responses from a pair of presynaptic SGC spikes ( 50 ms interstimulus interval). C, Amplitude histogram of 168 mossy cell EPSPs to the first SGC AP in the paired stimuli. The failure bar is truncated (76 failures). D, Histogram of the EPSP onset latency in the same paired recording.

near firing threshold (data not shown). The fast onset latency and low jitter $(0.30 \pm 0.12 \mathrm{~ms})$ strongly suggest that SGCs generate monosynaptic excitatory input to hilar cells. The probability of evoking an EPSP was $21.3 \pm 9.4 \%(n=4$ pairs $)$. The average postsynaptic response evoked by APs in SGCs facilitates with paired stimulation (mean paired-pulse ratio, $1.3 \pm 0.2 ; 50 \mathrm{~ms}$ interval) and was blocked by bath application of ionotropic glu- tamate receptor antagonists $(10 \mu \mathrm{M}$ NBQX $+50 \mu \mathrm{M}$ D-APV; $n=2$ pairs) (Fig. $3 B$, inset). The paired-pulse facilitation we observed after SGC activation is consistent with the general principle that low release probability CNS excitatory synapses often facilitate (Thomson, 2000).

The mean distances from visualized appositions to postsynaptic cell bodies are 88 $\mu \mathrm{m}(72$ and $104 \mu \mathrm{m})$ and $33 \mu \mathrm{m}$ (37 and $28 \mu \mathrm{m}$ ) for SGC-mossy cell and SGC-hilar interneuron pairs, respectively. SGC axon collaterals contacted both postsynaptic mossy cell dendrites beyond the first bifurcation (Fig. 3A, arrow indicates an SGC axon apposition with a mossy cell tertiary dendritic branch), suggesting that SGCs innervate relatively distal dendritic segments of mossy cells.

Simultaneous excitatory and inhibitory synaptic inputs after hilar stimulation We next sought to define the principal synaptic inputs to SGCs. Both SGCs and GCs respond to threshold stimulation in the middle molecular layer with EPSPs ( $n=9$ and 8 , respectively) (Fig. $4 A$, top), presumably reflecting perforant pathway (PP) inputs. The amplitudes $(1.47 \pm 0.11$ $\mathrm{mV}$ in SGCs vs $1.27 \pm 0.07 \mathrm{mV}$ in GCs; $p>0.05 ; n=5$ for each group) and onset latencies ( $1.79 \pm 0.08 \mathrm{~ms}$ in SGCs vs $1.93 \pm 0.04 \mathrm{~ms}$ in GCs; $p>0.05 ; n=5$ ) of these PP-evoked unitary EPSPs were similar in both cell types. Stimulation in the dentate hilus activated complex responses. Both threshold and suprathreshold stimulation in the hilus evoked inhibitory responses in SGCs and GCs (Fig. 4A, bottom) that appear to be composed of simultaneous IPSPs and EPSPs. Bath application of the $\mathrm{GABA}_{\mathrm{A}}$ receptor antagonist, gabazine, abolishes the IPSP and reveals a latent EPSP in both cell types $(n=$ $6)$. The EPSP component has a short onset latency (SGC latency, $2.08 \pm 0.10 \mathrm{~ms}$; GC latency, $2.68 \pm 0.73 \mathrm{~ms}$; not significantly different; $p>0.05$ ) and likely results from activation of hilar mossy cells. The hilarevoked EPSP in SGCs was significantly larger than the EPSP evoked in GCs at both threshold intensity (mean amplitude of successes, $1.36 \pm 0.22 \mathrm{mV}$ in SGCs vs $0.78 \pm 0.12 \mathrm{mV}$ in GCs; $n=6$ each; $p<$ 0.001 ; mean threshold intensities, 72 and $80 \mu \mathrm{A}$, respectively) (Fig. $4 B_{1}$ ) and at a fixed $(120 \mu \mathrm{A})$ stimulus intensity (mean amplitude, $6.9 \pm 0.90$ $\mathrm{mV}$ in SGCs vs $3.0 \pm 0.26 \mathrm{mV}$ in GCs; $p<0.001$ ) (Fig. $4 B_{2}$ ). Figure $4 C$ illustrates a typical threshold stimulus experiment with separable successes and failures in both SGC (left) and GC (right) recordings. The results from these experiments are summarized in Figure $4 D$ and show that SGCs receive stronger excitatory input from hilar axons than do GCs. Presumably, 
this EPSP reflects primarily direct input from mossy cells, although hilar stimulation may also antidromically activate SGC axons that innervate the IML.

\section{Discussion}

We make two principal conclusions in this study. First, although SGCs clearly share some morphological traits with GCs, they appear to represent a distinct cell type. SGCs differ from GCs in location and shape of their cell bodies, the lateral extent of dendritic arborization, and the presence of axon collaterals in the IML and GCL. SGCs also have less spike frequency adaptation and lower input resistance than GCs. Although not all SGC reconstructions show IML axon collaterals, SGCs were relatively homogenous in their electrophysiological properties. Second, SGCs receive a stronger excitatory input after hilar stimulation than GCs do. Because these stimuli likely activate mossy cell axons, this result suggests that SGCs are an important synaptic target of mossy cells, and therefore are potentially involved in epilepsy-related reorganization after seizure-induced loss of mossy cells.

\section{Are SGCs immature or ectopic} granule cells?

Because granule cells develop postnatally (Schlessinger et al., 1975), it is possible that the SGCs we find represent immature GCs. However, several lines of evidence suggest this is unlikely. First, granule cell neurogenesis occurs in the subgranular zone in the hilus, and newly born GCs incorporate into the GCL at the hilar border (Schlessinger et al., 1975). Second, intracellular recordings show that immature GCs have similar electrophysiological properties to mature GCs, except for a higher input resistance (Schmidt-Hieber et al., 2004). The SGCs we report have a lower input resistance than control GCs in the GCL and a constellation of different intrinsic properties. Immature GCs also have less extensive dendritic arborization than mature cells, and often have dendrites that fail to reach the fissure (Schmidt-Hieber et al., 2004; Shapiro and Ribak, 2005). In contrast, dendrites of SGCs have more extensive lateral spread than GC dendrites and extend to the fissure. As several studies (Green and Juraska, 1985; Claiborne et al., 1990; Shapiro and Ribak, 2005) suggest that the GCL contains a maturity gradient of granule cells (immature cells at the hilar border and mature cells closest to the IML), it is also possible that SGCs in the IML represent "elderly" GCs. However, our finding that SGCs exist in juvenile (P14) rats restricts the maximal possible age of GCs to $\sim 21 \mathrm{~d}$ (Schlessinger et al., 1975). It also is unlikely that SGCs represent ectopic GCs. Granule cells occasionally migrate into the hilus after seizure activity. How-

C
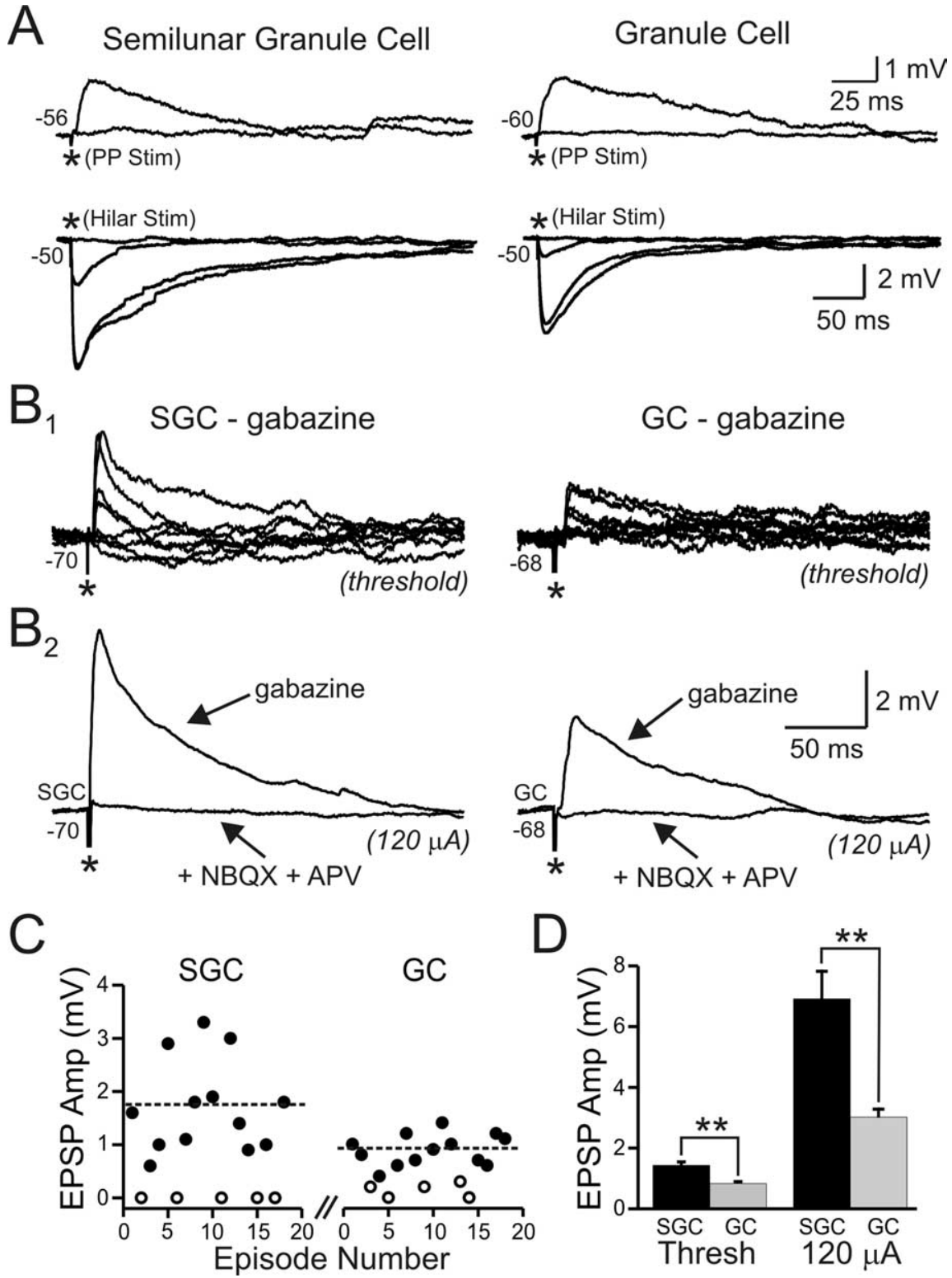

Figure 4. SGCs receive a larger excitatory synaptic input from hilar mossy cells than GCs. $A$, Threshold perforant path stimulation (PP Stim) evokes EPSPs and failures in both SGCs (top left; $63 \mu \mathrm{A}$ ) and GCs (top right; $64 \mu \mathrm{A}$ ). In contrast, graded hilar stimulation $(55,60,70$, and $80 \mu \mathrm{A})$ evokes IPSPs in both SGCs (bottom left) and GCs (bottom right). Asterisks indicate stimulus times. PP and hilar stimulation responses recorded from different $S G C S$ and $G C s$. B, Blockade of $G A B A_{A}$ receptors with gabazine (20 $\mu \mathrm{M})$ abolishes the IPSP response to hilar stimulation and reveals a short-latency EPSP onto both cells, presumably caused by activation of mossy cell axons. Both threshold $\left(\boldsymbol{B}_{\boldsymbol{1}}\right)$ and suprathreshold $\left(\boldsymbol{B}_{2}, 120 \mu \mathrm{A}\right)$ hilar stimulation in gabazine evoke larger amplitude EPSPs in SGCs than GCs. The excitatory response in gabazine is blocked by NBQX (10 $\mu \mathrm{m}$ ) and D-APV ( $50 \mu \mathrm{m}$; superimposed traces in $\boldsymbol{B}_{2}$ ). $\boldsymbol{C}$, Plot of the response amplitude versus episode number for the SGC and GC hilar stimulation experiments shown in $\boldsymbol{B}$. Filled circles represent successes; open circles, failures. Dashed lines indicate mean amplitudes of successes. $\boldsymbol{D}$, Summary graph of mean amplitude of successes with threshold stimulation and the mean of all responses after suprathreshold $(120 \mu \mathrm{A})$ hilar stimulation. ${ }^{* *} p<0.001$.

ever, intracellular recordings from these cells closely resemble normal GCs that are located in the GCL (Scharfman et al., 2000) and do not show the intrinsic physiological properties we find in SGCs.

One caveat in interpreting differences in spike frequency adaptation in GCs and GC-like neurons is sensitivity of these responses to exogenous Ca buffers. Although many sharp electrode studies of GC intrinsic properties (Dudek et al., 1976; Williamson et al., 1993; Buckmaster and Dudek, 1999) demonstrate pronounced spike frequency adaptation, responses with less adapta- 
tion are reported when high concentrations of Ca chelators are introduced into GCs through patch pipettes (Staley et al., 1992; Lübke et al., 1998). Because of these effects, we compared GC and SGC responses in identical internal solutions containing low $(0.2$ $\mathrm{mM}$ ) concentrations of EGTA. Also, it is unlikely that the primary functional difference between GCs and SGCs is simply different endogenous Ca buffer capacities as SGCs are physiologically distinct from BAPTA-filled GCs.

\section{Functional significance of SGCs}

Our results suggest that SGCs may provide an alternate pathway for entorhinal inputs to drive hilar neurons. SGCs have extensive dendrites in all three molecular layers and appear to receive excitatory PP inputs along with GCs. Our finding that hilar stimulation evokes large-amplitude EPSPs onto SGCs suggests that these neurons also receive excitatory input from mossy cells. The larger unitary EPSPs we find after hilar stimulation are consistent with the more proximal location of the mossy cell input (Scharfman, 1995). The large-amplitude mossy cell EPSP onto both cell types appears to be tightly regulated by near-simultaneous inhibition and is normally occluded by the hilar-evoked IPSP. This finding suggests that precise temporal sequence in which mossy cells and hilar interneurons are activated may have profound effects on the function of the hilar feedback projection to SGCs and GCs. The dramatic spike frequency adaptation present in GCs also limits both the time window for synaptic integration of these inputs and the potential for prolonged excitation resulting from the positive feedback loop between GCs and hilar mossy cells. Because SGCs do not self-limit their firing, they may integrate PP and mossy cell inputs over longer time intervals than GCs and may also participate in recurrent synaptic loops with hilar mossy cells.

Two critical questions that emerge from this study are which cell types are synaptic targets of SGC IML axon collaterals and whether SGCs are involved in epilepsy-related synaptic reorganization. Even using 2P-guided recordings, the large number of potential postsynaptic targets of visualized IML axon collaterals makes answering the first question technically challenging. The strong innervation SGCs appear to receive from mossy cells suggests that they may be an important target of sprouted GC axons. This hypothesis is likely to be testable in future studies by combining anatomical methods to stain GC axons with intracellular fills of SGCs in slices from epileptic animals.

\section{References}

Buckmaster PS, Dudek FE (1999) In vivo intracellular analysis of granule cell axon reorganization in epileptic rats. J Neurophysiol 81:712-721.

Claiborne BJ, Amaral DG, Cowan WM (1986) A light and electron microscopic analysis of the mossy fibers of the rat dentate gyrus. J Comp Neurol 246:435-458

Claiborne BJ, Amaral DG, Cowan WM (1990) Quantitative, threedimensional analysis of granule cell dendrites in the rat dentate gyrus. J Comp Neurol 302:206-219.

Dudek FE, Deadwyler SA, Cotman CW, Lynch G (1976) Intracellular re- sponses from granule cell layer in slices of rat hippocampus: perforant path synapse. J Neurophysiol 39:384-393.

Frazier CJ, Strowbridge BW, Papke RL (2003) Nicotinic receptors on local circuit neurons in dentate gyrus: a potential role in regulation of granule cell excitability. J Neurophysiol 89:3018-3028.

Green EJ, Juraska JM (1985) The dendritic morphology of hippocampal dentate granule cells varies with their position in the granule cell layer: a quantitative Golgi study. Exp Brain Res 59:582-586.

Houser CR, Miyashiro JE, Swartz BE, Walsh GO, Rich JR, Delgado-Escueta AV (1990) Altered patterns of dynorphin immunoreactivity suggest mossy fiber reorganization in human hippocampal epilepsy. J Neurosci 10:267-282.

Jiao Y, Nadler JV (2007) Stereological analysis of GluR2-immunoreactive hilar neurons in the pilocarpine model of temporal lobe epilepsy: correlation of cell loss with mossy fiber sprouting. Exp Neurol 205:569-582.

Lübke J, Frotscher M, Spruston N (1998) Specialized electrophysiological properties of anatomically identified neurons in the hilar region of the rat fascia dentata. J Neurophysiol 79:1518-1534.

Pressler RT, Strowbridge BW (2006) Blanes cells mediate persistent feedforward inhibition onto granule cells in the olfactory bulb. Neuron 49:889-904.

Ramón y Cajal S (1995) Histology of the nervous system. New York: Oxford UP.

Scharfman HE (1995) Electrophysiological evidence that dentate hilar mossy cells are excitatory and innervate both granule cells and interneurons. J Neurophysiol 74:179-194.

Scharfman HE, Schwartzkroin PA (1988) Electrophysiology of morphologically identified mossy cells of the dentate hilus recorded in guinea pig hippocampal slices. J Neurosci 8:3812-3821.

Scharfman HE, Kunkel DD, Schwartzkoin PA (1990) Synaptic connections of dentate granule cells and hilar neurons: results of paired intracellular recordings and intracellular horseradish peroxidase injections. Neurosci 37:693-707.

Scharfman HE, Goodman JH, Sollas AL (2000) Granule-like neurons at the hilar/CA3 border after status epilepticus and their synchrony with area CA3 pyramidal cells: functional implications of seizure-induced neurogenesis. J Neurosci 20:6144-6158.

Schlessinger AR, Cowan WM, Gottlieb DI (1975) An autoradiographic study of the time of origin and the pattern of granule cell migration in the dentate gyrus of the rat. J Comp Neurol 159:149-175.

Schmidt-Hieber C, Jonas P, Bischofberger J (2004) Enhanced synaptic plasticity in newly generated granule cells of the adult hippocampus. Nature 429:184-187.

Shapiro LA, Ribak CE (2005) Integration of newly born dentate granule cells into adult brains: hypotheses based on normal and epileptic rodents. Brain Res Brain Res Rev 48:43-56.

Sloviter RS (1992) Possible functional consequences of synaptic reorganization in the dentate gyrus of kainate-treated rats. Neurosci Lett 137:91-96.

Staley KJ, Otis TS, Mody I (1992) Membrane properties of dentate gyrus granule cells: comparison of sharp microelectrode and whole-cell recordings. J Neurophysiol 67:1346-1358.

Tauck DL, Nadler JV (1985) Evidence of functional mossy fiber sprouting in hippocampal formation of kainic acid-treated rats. J Neurosci 5:1016-1022.

Thomson AM (2000) Faciliation, augmentation and potentiation at central synapses. Trends Neurosci 23:305-312.

Williamson A, Spencer DD, Shepherd GM (1993) Comparison between the membrane and synaptic properties of human and rodent dentate granule cells. Brain Res 622:194-202. 